\title{
Future-oriented emotions: Conceptualization and behavioral effects
}

\author{
HANS BAUMGARTNER ${ }^{1}$, \\ RIK PIETERS ${ }^{2 *}$ AND RICHARD P. BAGOZZI ${ }^{3}$ \\ ${ }^{1}$ Pennsylvania State University, USA \\ ${ }^{2}$ Tilburg University, The Netherlands \\ ${ }^{3}$ University of Michigan, USA
}

\section{Abstract}

We distinguish between two kinds of future-oriented emotions (anticipatory and anticipated) and investigate their behavioral effects. Anticipatory emotions are currently experienced due to the prospect of a future event (e.g., hope or fear). Anticipated emotions, on the other hand, are expected to be experienced in the future if certain events do or do not occur (e.g., anticipated joy or regret). We discuss the theoretical differences between the two types of future-oriented emotions and examine their role in motivating goal-directed behavior. The results of a longitudinal study $(n=472)$ and a separate control group analysis $(n=340)$ provide consistent support for the convergent and discriminant validity of positive/negative anticipatory and anticipated emotions and their independent influence on goal-directed behavior. Copyright (C) 2007 John Wiley \& Sons, Ltd.

Sometimes people fear that an undesirable future event may happen, or hope that it will not, and they imagine the behaviors that they can perform to avert the impending danger and visualize their relief or joy when the negative outcome does not materialize. All these affective reactions to future events may influence goal-directed behavior.

This research is about the motivational effects of such future-oriented emotions, defined as affective reactions to future events. Although several researchers have speculated about the role of emotions in the goal-action cycle (e.g., Carver \& Scheier, 2002; Lazarus, 1991), and even though some studies have investigated the motivational influence of specific future-oriented emotions such as anticipated regret and disappointment (e.g., Abraham \& Sheeran, 2004; Richard, van der Pligt, \& de Vries, 1996; Zeelenberg, 1999; Zeelenberg \& Pieters, 2004), we still know little about the different kinds of future-oriented emotions and their role in goal-directed behavior.

More specifically, the present research aims to make the following two contributions. First, we build on recent proposals (e.g., Loewenstein \& Lerner, 2003) to distinguish two types of future-oriented emotions. Although the distinction is implicit in earlier writings (e.g., Atkinson, 1964), only recently have researchers begun to articulate the differences between them. We will call the two kinds of future-oriented affective reactions anticipatory and anticipated emotions. On the one hand, a person may currently experience an emotion due to the prospect of a desirable or undesirable future event (i.e., hope or fear). These affective reactions are anticipatory emotions, because they are currently experienced due to something that could happen in the future. On the other hand, a person may imagine experiencing certain emotions in the future once certain desirable or undesirable future events have occurred (e.g., anticipated joy or regret). These affective reactions are anticipated emotions. To our knowledge, the current study is the first attempt to study anticipatory and anticipated emotions empirically and to establish their convergent and discriminant validity.

*Correspondence to: Rik Pieters, Tilburg University, Faculty of Economics and Business, Warandelaan 2, Tilburg, 5000 LE, The Netherlands. E-mail: pieters@uvt.nl 
Second and most importantly, we consider the role of anticipatory and anticipated emotions in goal pursuit and seek to establish their predictive validity. Although previous research has shown that each type of emotion can motivate future behavior (e.g., Abraham \& Sheeran, 2004; Bagozzi, Baumgartner, \& Pieters, 1998; Gleicher, Boninger, Strathman, Armor, \& Ahn, 1995; van der Pligt, Zeelenberg, van Dijk, de Vries, \& Richard, 1998; Zeelenberg \& Pieters, 2004), anticipatory and anticipated emotions have not been compared in a single study, and their relative effectiveness in stimulating goal-directed behavior is thus uncharted.

We report the results of a study involving two large samples of respondents to assess the convergent and discriminant validity of anticipatory and anticipated emotions, and to examine their predictive validity in goal-directed behavior. The context for the study was a major societal event, the millennium change of 1999-2000.

\section{ANTICIPATORY AND ANTICIPATED EMOTIONS ABOUT FUTURE EVENTS}

Although at face value, anticipatory and anticipated emotions are clearly different, the two concepts are, in our view, fuzzy sets for which no necessary and sufficient criteria of category membership are available (Fehr \& Russell, 1984). However, we posit that certain features are characteristic of the two types of future-oriented emotions, which we will discuss in this section. These characteristics deal with (a) the role of uncertainty, (b) the phenomenology of the emotion, and (c) the range of discrete emotions subsumed in each category.

First, anticipatory emotions are current affective responses to the prospect of future events that have positive or negative consequences (Ortony, Clore, \& Collins, 1988). Therefore, uncertainty about what is going to happen constitutes part of the meaning of anticipatory emotions, in the sense that the feeling of uncertainty per se partially causes the emotion (i.e., anticipatory hope in the case of desired events and anticipatory worry in the case of undesired events; see Roseman, Antoniou, \& Jose, 1996; Smith \& Ellsworth, 1985). In contrast, anticipated emotions do not involve any uncertainty because they are based on the assumption, through mental simulation, that the future event has already happened or will not happen. The person imagines how good or bad it would feel to experience certain outcomes, given that the imagined future event has actually occurred. To the extent that likelihood comes into play, it is distinct from the emotion itself ('How would I feel if X happened?'). This is similar to the distinction of valuation and expectation found in expectancy-value models.

Second, anticipatory emotions are always currently experienced, phenomenologically real affective responses to possible future events that have positive or negative implications for the self. For instance, one may worry about the prospect of losing one's job because of rumors of an impending plant closure. In contrast, anticipated emotions are based on pre-factual thinking about imagined positive or negative consequences. Although they could be real emotional experiences based on vivid visualizations of possible futures, often they are predictions, or affective forecasts (e.g., Gilbert, Pinel, Wilson, Blumberg, \& Wheatley, 1998; Wilson \& Gilbert, 2003), about one's future emotions based on imagined states of the world and their personal implications. For instance, one may visualize having just won the lottery and anticipate the joy one would feel in this situation, without experiencing other components of emotions such as emotivational goals and action tendencies (Frijda, 2004; Roseman et al., 1996).

Third, the range of anticipatory emotions is smaller than the range of anticipated emotions. Anticipatory emotions are a specific subset of all discrete emotions that people may experience, namely, those related to the prospect of future events (expectant promises and impending dangers). In contrast, in the case of anticipated emotions, any discrete emotion that can be experienced may be anticipated in advance, based on a mental simulation of future outcomes. For example, a person may anticipate satisfaction when imagining a positive outcome, guilt when visualizing a blameworthy action, or regret when imagining a decision gone awry.

Based on these distinctions, we propose that hope and fear are the prototypical categories of positive and negative anticipatory emotions, respectively (Ortony et al., 1988). Hope reflects pleasure about the prospect of a desired future event. Specific emotional facets are, for example, anticipatory excitement and feelings of optimism, confidence, or relaxation (Carver \& Scheier, 2002; Ortony et al., 1988; Plutchik, 1980; Snyder \& Lopez, 2002). In contrast, fear indicates displeasure about the prospect of an undesired future event (Lazarus, 1991). Specific facets include worry, anxiety, nervousness, and tension or stress (Averill, Catlin, \& Chon, 1990; Ortony et al., 1988; Plutchik, 1980; Shaver, Schwartz, 
Kirson, \& O'Connor, 1987). Anticipation (hope) and fear are opposite in Plutchik's (1980) circumplex model of primary emotions.

Although in principle any experienced emotion can be anticipated, some emotions are more likely than others to function as anticipated emotions in goal-directed behavior. Using the framework developed by Ortony et al. (1988), we propose the following anticipated emotions as relevant for goal-directed behavior. First, some emotions are experienced when a prediction about a desired or undesired future event is confirmed or disconfirmed. Although these emotions usually occur when an event actually happens, based on pre-factual thinking such confirmations or disconfirmations can also be anticipated. For example, anticipated satisfaction reflects confirmed expectations about a desirable future, anticipated disappointment reflects disconfirmed expectations about a desirable future, anticipated fears-confirmed reflects confirmed expectations about an undesirable future, and anticipated relief reflects disconfirmed expectations about an undesirable future. Second, there are event-based emotions, such as joy and distress, for which prospects are not relevant but outcomes are important. These emotional reactions may be anticipated as well. Third, since our interest is in the behavioral effects of future-oriented emotions and since simulations of future events may include visualizing what one has or has not done to bring about or avert certain consequences, affective responses indicating approval or disapproval of one's actions, such as pride or guilt, may be experienced or imagined as well.

In sum, with respect to anticipatory emotions, people at present experience emotions due to the likelihood that a desirable or undesirable event may happen in the future. With respect to anticipated emotions, people at present imagine the emotions they would experience in the future under the assumption that a desirable or undesirable event has happened. Because of our aim to differentiate anticipatory from anticipated emotions, both conceptually and empirically, the focus in the empirical part will be on positively and negatively valenced emotions, rather than on specific, discrete emotions. However, instead of using general feelings measures such as semantic differential scales (e.g., Richard et al., 1996), we will employ specific (unipolar) emotion terms, derived from the previous discussion, to cover the spectrum of affective reactions that people may experience or anticipate due to future events.

\section{MOTIVATIONAL EFFECTS OF FUTURE-ORIENTED EMOTIONS}

The predicted effects of anticipatory emotions on behavior derive from the motivational tendencies associated with fear and hope. With regard to hope, Lazarus (1991) argues that, although a clear action tendency cannot easily be specified for hope, approaching and staying committed to the desired outcome might result from hope. Research by Averill et al. (1990) on the action rules of hope supports this, indicating that '[p]eople who hope should be willing to take appropriate action to achieve their goals, if action is possible' (p. 34). Participants reported that the primary action taken as a consequence of hope was working harder and being more persistent in one's effort, and this was especially the case for participants who experienced personal control over the situation. Based on this, we predict that positive anticipatory emotions will encourage the formation of behavioral intentions aimed at bringing about a desirable future state.

With regard to fear, researchers agree that fear engenders a desire to escape from or avoid an aversive state (Frijda, Kuipers, \& ter Schure, 1989; Lazarus, 1991; Öhman, 2000; Plutchik, 1980; Roseman et al., 1996). In particular, the large body of work on fear-arousing persuasive messages supports the notion that an increase in fear (as assessed by both manipulations and measures of fear) prompts danger-control strategies, which have a positive influence on attitudes, intentions, and behavior (for reviews see Boster \& Mongeau, 1984; Milne, Sheeran, \& Orbell, 2000; and Sutton, 1982). Therefore, we hypothesize that negative anticipatory emotions will lead to the formation of behavioral intentions aimed at avoiding undesirable future states.

Previous research is consistent with the idea that anticipated emotions can motivate goal-directed behavior as well. Within the context of Fishbein and Ajzen's (1975) theory of reasoned action and its variants (e.g., Ajzen, 1991), Parker, Manstead, and Stradling (1995), Perugini and Bagozzi (2001), and Richard et al. (1995, 1996) have shown that anticipated emotions increase intentions, behavioral expectations, or desires to act, even when controlling for other determinants of behavior such as attitudes, subjective norms, perceived behavioral control, or past behavior. For example, in an influential study by Richard et al. (1995) participants who anticipated negative emotions about having had sex without using a condom indicated significantly higher expectations to use condoms than those who anticipated less negative feelings. In a similar fashion, but using cognitive appraisal theories of emotions as a theoretical guide, Bagozzi et al. (1998) presented 
evidence that both positive and negative anticipated emotions evoked by imagined success or failure experiences in goal pursuit increased volitions (plans, intentions, and effort) to engage in weight control. ${ }^{1}$

Motivational effects of specific, discrete anticipated emotions have been documented as well, in particular for anticipated regret. For example, Abraham and Sheeran (2004) showed that anticipated regret predicted intentions to engage in health-enhancing behavior, even after controlling for other determinants.

Finally, the mental simulation literature also suggests that imagining events often evokes strong emotions and that the action tendencies intrinsically linked to these emotions may be responsible for the beneficial behavioral effects of visualizing the future. As Taylor and Pham put it, the emotions may 'provide the fuel for bringing about effective action' (1996, p. 232). One particular mechanism is based on what Gleicher et al. (1995) call prefactuals. Prefactuals are like counterfactuals, except that they refer to imagined future events. For example, a person who plans to lose weight may imagine having been unsuccessful in losing weight, and the anticipated negative emotions associated with this failure may stimulate coping behaviors to prevent this letdown. Gleicher et al. (1995) argue that the particular structure of prefactuals may give them some advantages over other types of (outcome) simulations. Similar to outcome simulations in general, the consequent of a pre-factual refers to a desired or undesired outcome associated with affect, but in addition the antecedent often specifies the behaviors responsible for the outcome (e.g., If I had done X, Y would have happened). In this way, prefactuals combine a motivating outcome with a specific course of action that promises to lead to that outcome. Since anticipated emotions include the required actions to produce them, they may increase the likelihood of performing them.

In summary, we argue for a conceptual distinction between two types of future-oriented emotions, anticipatory and anticipated. The prototypical anticipatory emotions are hope and fear, which are 'real' emotions that are phenomenologically experienced in the present due to the prospect of desired or undesired future events, with uncertainty being a key ingredient in the experience of the emotion. In contrast, anticipated emotions can include any discrete emotion that may be experienced in response to the assumed (certain) occurrence of a desired or undesired future event. Uncertainty is not part of the experience of the emotion, and frequently the emotion is 'virtual' in the sense that it consists of one's forecast of an affective reaction to a future scenario only, without the thoughts, feelings, emotivational goals, and action tendencies that accompany 'real' emotions (Frijda, 2004). We also argue that both types of emotions can motivate future behavior and that they independently influence goal-directed behavior through their influence on behavioral intentions. We now describe a study that was designed to establish the distinct empirical status of anticipatory and anticipated emotions and test their separate effects on behavior.

\section{METHOD}

The data were collected in the context of the millennium transition in 1999-2000 (the so-called Y2K problem). Prior to the date change, there was widespread concern and uncertainty about the consequences of rolling over the digits from ' 99 ' to '00' in the world's computers, and people were advised to '[h]ope for the best, but plan for the worst' (Hyatt, 1998, p. 208). This made the millennium transition an ideal context for studying future-oriented emotions.

\section{Participants}

A total of 812 members of the CentER Data panel at Tilburg University participated in a two-wave longitudinal study. Panel members, representative of the Dutch population, received and returned questionnaires on their personal computers. The 812 participants were randomly assigned to a longitudinal group $(n=472)$ and a control group $(n=340)$. The control group was used to establish the reliability as well as convergent and discriminant validity of positive and negative anticipatory and anticipated emotions. Therefore, control-group respondents were included in the first wave only and completed only the items about emotions, as described below. The longitudinal group was used to establish the predictive validity of positive and negative anticipatory and anticipated emotions. Therefore, respondents in the longitudinal group participated in both waves and completed all questions. Using two separate groups to establish convergent and

${ }^{1}$ Bagozzi et al. (1998) do not draw a distinction between anticipatory and anticipated emotions and seem to use the two terms interchangeably. However, their conceptualization and particularly operationalization of goal-directed emotions is most consistent with the present notion of anticipated emotions. 
discriminant validity on the one hand and predictive validity on the other hand is conservative, and minimizes the likelihood of overusing the data.

\section{Design and Measures}

The first wave of data collection was during the first week of November 1999, about 7 weeks prior to the millennium change. After a brief description of the millennium transition and a screening question to make sure that everybody had heard about the issue (all had), we collected data on the following constructs in the following order: likelihood of various negative outcomes; anticipatory emotions; anticipated emotions; behavioral intentions to prepare for the millennium change; and future (trait) anxiety. Control-group participants responded only to the emotion questions.

\section{Likelihood of Negative Outcomes}

Participants rated how likely it was that the millennium change would have various negative outcomes for the Netherlands and for them personally during the first few days of 2000. This allows us to test the prediction that anticipatory emotions, but not anticipated emotions, are dependent on likelihood appraisals. In addition, it allows us to examine whether anticipatory and anticipated emotions motivate behavior, over and above the important cognitive factor of likelihood estimates. A 7-point scale with endpoints of 'very unlikely' (1) and 'very likely' (7) was used for each of the likelihood items. Based on a review of the Y2K literature, the likelihood ratings were collected for seven specific areas: (1) airplane, car, train, tram, and ferry travel (e.g., traffic jams); (2) financial business (e.g., problems with withdrawing or depositing cash); (3) government agencies and health care (e.g., unavailability of medical information about patients); (4) supply of stores (e.g., shortages of certain products); (5) supply of natural gas, water, electricity, cable, etc. (e.g., black-outs); (6) communication (e.g., problems with telephone); and (7) road travel (e.g., accidents). In addition, there were two overall questions about the likelihood of negative outcomes, one for the Dutch economy and society in general and one for participants personally.

\section{Anticipatory Emotions}

Participants rated how worried, anxious, and uncomfortable (for negative anticipatory emotions) and how optimistic and confident (for positive anticipatory emotions; see Ortony et al., 1988; Shaver et al., 1987) they were that the millennium transition would have (no) negative outcomes for them personally during the first days of 2000. The ratings were collected using 7-point response scales with endpoints of 'not at all' (1) and 'very much' (7).

\section{Anticipated Emotions}

Participants were asked to imagine that it was the first week of 2000 and that the millennium change had caused certain problems in the Netherlands. For positive anticipated emotions, participants were told to assume that they had succeeded in avoiding or limiting the negative outcomes caused by the millennium change because of what they had done (thus combining process and outcome simulation; see Taylor \& Pham, 1996), and they indicated how relieved, satisfied, happy, and proud they would feel (Ortony et al., 1988; Bagozzi et al., 1998). For negative anticipated emotions, participants were told to assume that they had done nothing to avoid or limit the negative outcomes of the millennium transition, and they indicated how disappointed, annoyed, regretful, stupid, guilty, and angry with themselves they would feel because of it (Bagozzi et al., 1998; Ortony et al., 1988). The ratings were collected using 7-point scales with endpoints of 'not at all' (1) and 'very much' (7).

\section{Behavioral Intentions}

Participants were asked to indicate, using 7-point scales ranging from 'certainly not' (1) to 'certainly so' (7), whether they would do certain things in order to avoid or limit the possible negative outcomes caused by the millennium transition. The 
behaviors, derived from the Y2K literature (e.g., Hyatt, 1998), were: (1) getting extra cash to be able to make payments; (2) building an extra supply of batteries, candles, fire wood, propane gas, and water; (3) building an extra supply of food products, such as coffee, sugar, bread, potatoes, and cheese; (4) having someone check whether one's computer or other electronic equipment at home can cause trouble; (5) taking days off from work during the first week of January; (6) making extra copies of important documents, such as medical information; (7) avoiding traveling by car, plane, or public transportation during the first few days of 2000; and (8) checking whether one's banks and insurance companies have taken the necessary precautions. In addition, there was an overall behavioral intention question that asked how much participants were planning to do in order to avoid or limit the expected problems caused by the millennium transition. The response alternatives on this question ranged from 'do nothing' (1) to 'do very much' (7).

\section{Future Anxiety}

To control for individual differences in dispositional negative anticipatory emotions, we included a 12-items short-form version of the Zaleski's (1996) scale of future anxiety (e.g., 'I am afraid that some catastrophe will soon occur'). Participants provided the ratings on a scale from 'decidedly false' (1) to 'decidedly true' (7). The inclusion of trait anxiety allows us to examine how anticipatory emotions are related to dispositional determinants, and whether future-oriented emotional states motivate behavior over and above a theoretically related dispositional factor.

The second wave of data collection was administered in early January during the weekend following the millennium change, 2 months after the first wave. The behavioral data were collected at this stage.

\section{Behavior}

Participants indicated how much they had done prior to January 1st in order to avoid or limit the negative outcomes of the millennium transition. Participants considered their behavior in the same eight areas that had been used in the behavioral intention questions in the first wave, and they provided their answers on 7-point scales ranging from 'not at all' (1) to 'very much' (7). They also assessed their behavior overall, using a scale with endpoints of 'done nothing' (1) to 'done very much' (7).

\section{RESULTS}

\section{Structure of Anticipatory and Anticipated Emotions: Convergent and Discriminant Validity}

We specified a confirmatory factor model, using the data of the control group $(n=340)$, to investigate the validity and reliability of measurement of the four future-oriented emotions factors: positive and negative anticipatory emotions, and positive and negative anticipated emotions (see Figure 1). The analysis was conducted with LISREL 8.8, using the Satorra-Bentler scaled chi-square statistic and robust standard errors to correct for non-normality of the data. The fit of the four-factor model was adequate, with $\chi^{2}(84)=242.69, \mathrm{CFI}=.97, \mathrm{RMSEA}=.075$ (90 per cent confidence interval from .064 to .086 ), $\mathrm{SRMR}=.038$. These values exceed, or are close to, the standards commonly suggested in the literature (i.e., CFI should exceed .95, RMSEA should be below .06, and SRMR should be smaller than .08; see Hu \& Bentler, 1999). All loadings on target factors were highly significant (smallest $t$-value $=12.90$ ), and the average completely standardized factor loading was .85 (smallest loading = .72). The largest (absolute) non-target loading was .11 (based on the expected parameter change statistic). The coefficient alpha reliabilities were as follows: positive anticipatory emotions .72; negative anticipatory emotions .93; positive anticipated emotions .92; negative anticipated emotions .94. These findings support the conclusion that the four types of future-oriented emotions were measured reliably.

The means of the items measuring each emotion factor show that participants, on average, were hopeful that nothing would happen (5.50 on a 7-point scale) and did not worry much about possible negative outcomes (1.95). The intensities of positive and negative anticipated emotions were around the midpoint of the scale (4.44 and 3.45, respectively). 


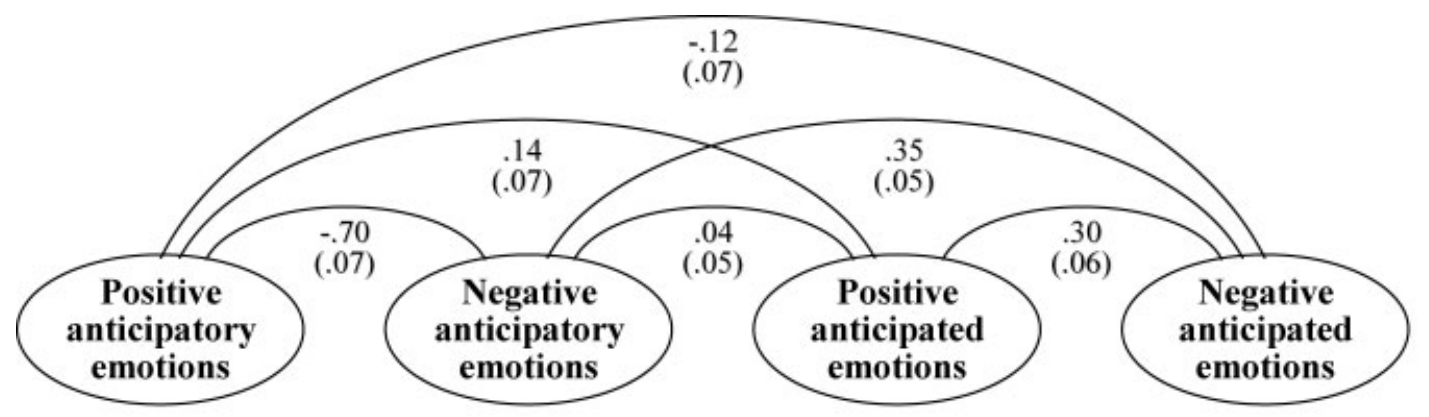

\section{Optimistic (.77) \\ Confident (.73)}

\author{
Worried (.92) \\ Anxious (.94) \\ Uncomfortable (.85)
}

\author{
Relieved (.89) \\ Satisfied (.93) \\ Happy (.92) \\ Proud (.72)
}

\author{
Disappointed (.76) \\ Annoyed (.87) \\ Regretful (.83) \\ Stupid (.91) \\ Guilty (.86) \\ Angry at self (.91)
}

Figure 1. Factor model for future-oriented emotions. Note: Hypothesized constructs are shown as ellipses. Figures underneath non-directed arcs between ellipses refer to correlations between the constructs, with robust standard errors in parentheses. Emotion words below the ellipses refer to the items used to measure each construct. Figures in parentheses are factor loadings from the completely standardized solution, in which both the factors and observed variables are standardized to a variance of 1

Importantly, the pattern of correlations between the four emotion factors further supports the distinction between the two types of future-oriented emotions. Specifically, positive and negative anticipatory emotions were strongly negatively correlated $(-.70, p<.001)$, demonstrating that respondents who were hopeful and confident that nothing would happen also felt little fear or worry about possible negative outcomes of Y2K. On the other hand, the correlation between positive and negative anticipated emotions was positive $(.30, p<.001)$, revealing that these two emotions were coordinated, due to the overall goal to attain either good outcomes or avoid bad outcomes in the mental simulations. In addition, we also found that negative anticipatory and anticipated emotions were positively correlated $(.35, p<.001)$, which suggests that the more worried people were about Y2K (anticipatory), the worse they felt about the imagined negative consequences of the millennium problem in case they were to act ineffectively (anticipated). Alternatively, people who forecast feeling bad about assumed negative consequences were more worried. All other correlations were non-significant at the 5 per cent level (see Figure 1 for the specific results). ${ }^{2}$ Overall, these findings demonstrate the reliability and convergent and discriminant validity of the two types of future-oriented emotions.

\section{Behavioral Effects of Future-Oriented Emotions: Predictive Validity}

The structural model, tested on the longitudinal group $(n=472)$, is shown in Figure 2. Of primary interest are the direct effects of positive/negative anticipatory and anticipated emotions on behavioral intentions. The prediction is that all four emotions will independently encourage the formation of intentions to engage in behavior aimed at averting possible negative consequences of the millennium transition. We did not expect direct effects of the future-oriented emotions on actual behavior since the effects of emotions on behavior are generally mediated by volitional variables such as behavioral intentions (e.g., Bagozzi et al., 1998). However, because we do predict a positive effect of intentions on behavior, we expect and test for indirect effects of future-oriented emotions on behavior (as mediated by behavioral intentions), and explore the possibility of direct effects of future-oriented emotions on behavior.

\footnotetext{
${ }^{2}$ Separate analyses for males $(n=181)$ and females $(n=159)$ revealed the same factor structure, loadings, correlations, and means for both genders.
} 


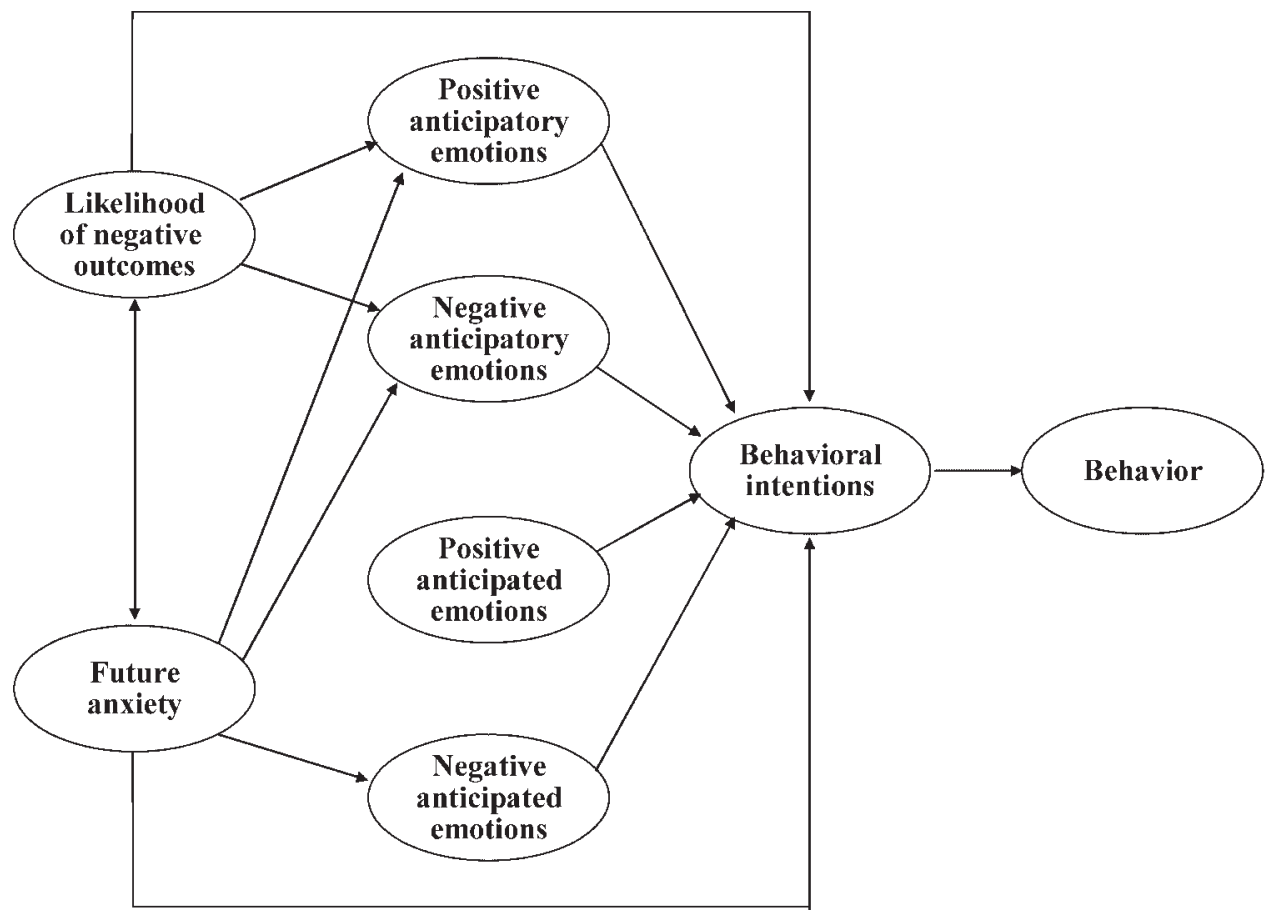

Figure 2. Antecedents and consequences of future-oriented emotions. Note: Correlations between the four types of future-oriented emotions (i.e., correlations between the error terms of the four emotions) are not shown for simplicity

In addition to the constructs of primary interest, the proposed model also included two additional constructs (likelihood of negative consequences and future anxiety) that served as control variables. Since future anxiety is a stable emotional trait, it was specified as an antecedent of the more temporary future-oriented emotion factors. Consistent with the earlier discussion of the role of uncertainty in the experience of future-oriented emotions, we also expected that the intensity of anticipatory emotions (but not the intensity of anticipated emotions, because uncertainty is not part of the meaning structure for these emotions) would be a function of the judged likelihood of negative outcomes. Finally, likelihood of negative consequences and future anxiety were allowed to directly influence behavioral intentions. ${ }^{3}$

Preliminary analyses indicated that the individual intention and behavior measures were internally consistent (coefficient alphas of .83 and .72, respectively), so to simplify the analysis they were averaged to form overall intention and behavior composites (Bagozzi \& Heatherton, 1994). The reliabilities of likelihood of negative outcomes and future anxiety were also adequate (coefficient alphas of .91 and .85 , respectively). In addition, a confirmatory factor analysis of the emotion measures for this longitudinal group confirmed the findings of the analysis for the control group that positive and negative variants of the two types of future-oriented emotions can be assessed validly and reliably. The overall fit measures were acceptable $\left(\chi^{2}(84)=251.40 ; \mathrm{CFI}=.98 ; \mathrm{RMSEA}=.065\right.$, with a 90 per cent confidence interval from .056 to $.074 ;$ SRMR $=.037$ ), and the coefficient alpha reliabilities were as follows: positive anticipatory emotions .79; negative anticipatory emotions .93; positive anticipated emotions .91; negative anticipated emotions .95 . As in the control group analysis, positive and negative anticipatory emotions were correlated negatively $(-.57, p<.001)$, and positive and negative anticipated emotions were correlated positively $(.38, p<.001)$. The correlations between the two positive emotions $(.18, p<.001)$ and the two negative emotions $(.28, p<.001)$ were also significant.

\footnotetext{
${ }^{3}$ Figure 2 shows the final model selected as the best representation of the data. Initially, we started with a model in which likelihood of negative outcomes was freely correlated with future anxiety, the four emotion factors were allowed to correlate (by correlating their error terms), anticipatory emotions were a function of the likelihood of negative consequences and future anxiety, behavioral intentions were a function of the four emotion factors, and behavior was a function of behavioral intentions. We then respecified the model based on significant modification indices, provided the change made substantive sense. In response to a suggestion by one of the reviewers, we also performed some additional validation analyses. Specifically, we randomly split the total sample in half, developed a well-fitting specification using one half as the calibration sample, and then cross-validated the model using the other half. This procedure confirmed the specification of the model shown in Figure 2.
} 
Table 1. Antecedents and consequences of future-oriented emotions: path analysis results

\begin{tabular}{|c|c|c|c|}
\hline Path & $\begin{array}{l}\text { Unstandardized } \\
\text { path coefficient }\end{array}$ & $t$-value & $\begin{array}{c}\text { Standardized } \\
\text { path coefficient }\end{array}$ \\
\hline Likelihood of negative outcomes $\rightarrow$ positive anticipatory emotions & -.27 & -4.13 & -.23 \\
\hline Likelihood of negative outcomes $\rightarrow$ behavioral intentions & .32 & 7.15 & .31 \\
\hline Future anxiety $\rightarrow$ positive anticipatory emotions & -.21 & -3.02 & -.14 \\
\hline Future anxiety $\rightarrow$ negative anticipatory emotions & .28 & 5.25 & .24 \\
\hline Future anxiety $\rightarrow$ behavioral intentions & .12 & 2.01 & .09 \\
\hline Positive anticipatory emotions $\rightarrow$ behavioral intentions & -.01 & -.20 & -.01 \\
\hline Negative anticipatory emotions $\rightarrow$ behavioral intentions & .16 & 2.73 & .15 \\
\hline Positive anticipated emotions $\rightarrow$ behavioral intentions & .10 & 3.16 & .12 \\
\hline Negative anticipated emotions $\rightarrow$ behavioral intentions & .18 & 6.50 & .27 \\
\hline Behavioral intentions $\rightarrow$ behavior & .17 & 6.44 & .36 \\
\hline
\end{tabular}

Note: All $t$-values $>2.0$ are significant at $p<.05$.

The final structural model presented in Figure 2, which includes only the paths that were significant (except for the hypothesized path from positive anticipatory emotions to behavioral intentions) fit the data well: $\chi^{2}(9)=12.08$; $\mathrm{CFI}=.99$; RMSEA $=.027$; SRMR .031 . More importantly, as shown in Table 1, the estimated path coefficients confirm most of the hypotheses. To begin with, negative anticipatory emotions and positive and negative anticipated emotions all have positive effects on behavioral intentions. This means that participants who were fearful about possible negative consequences of the millennium transition and who experienced stronger emotional reactions to a mental simulation of the positive and negative outcomes of the millennium change also indicated that they were more motivated to engage in behaviors aimed at averting the threat. Only the predicted positive effect of hope on behavioral intentions was not empirically supported.

Table 1 also shows that, as expected, the judged likelihood of negative outcomes was negatively related to positive and positively related to negative anticipatory emotions. In contrast, the likelihood of negative outcomes had no impact on anticipated emotions (both modification indices were non-significant). Future anxiety had a dampening effect on positive and an intensifying effect on negative anticipatory emotions. Furthermore, future anxiety increased the intensity of negative anticipated emotions. Jointly, this demonstrates that dispositional worriers are more likely to experience anticipatory emotions and also that they are particularly good at imagining or even experiencing negative emotions in response to simulated future events. Both the likelihood of negative outcomes and future anxiety had direct positive effects on behavioral intentions, although the magnitude of the latter effect was small. Importantly, the predicted influence of positive and negative future-oriented emotions emerged even while controlling for a strong cognitive factor (likelihood judgments) and strong affective trait (future anxiety). Intentions also had the predicted positive effect on self-reported behavior.

The specified model accounts for 38 per cent of the variance in intentions and 13 per cent of the variance in behavior. Although behavior has only one direct antecedent (behavioral intentions), the indirect effects of likelihood of negative outcomes $(.07, t$-value $=5.37)$, future anxiety $(.05, t$-value $=3.60)$, negative anticipatory emotions $(.03, t$-value $=2.57)$, positive anticipated emotions $(.02, t$-value $=2.94)$, and negative anticipated emotions $(.03, t$-value $=4.42)$ are all statistically significant. It should be emphasized that behavior was assessed about 2 months after the other variables, so these relationships are unlikely to be due to consistency biases, which strengthens the findings. Likelihood of negative outcomes had the largest total effect on behavioral intentions (.40), followed by future anxiety (.27), negative anticipated emotions (.18), negative anticipatory emotions (.16), and positive anticipated emotions (.10).

\section{DISCUSSION}

The present research makes several contributions to the emotion literature, in particular concerning the structure and motivational implications of emotions. It is, to our knowledge, the first empirical study to establish the construct validity of positive and negative anticipatory and anticipated emotions, and the first attempt to assess their predictive validity for 
goal-directed behavior. We identified essential differences between the two types of future-oriented emotions, equating the positively and negatively valenced forms of anticipatory emotions to hope and fear, respectively, and defining anticipated emotions as any emotional reaction to mental simulations of future events and behaviors. We proposed that both anticipatory and anticipated emotions would encourage the formation of intentions to engage in behavior aimed at bringing about or averting the future events at which these emotions are directed. Most importantly, the empirical analyses revealed that positively and negatively valenced anticipatory and anticipated emotions can be measured reliably, are empirically distinct, and relate to other constructs in the hypothesized way. For example, the likelihood that the target event will occur was shown to influence the experience of anticipatory emotions, but was unrelated, or much more weakly related, to anticipated emotions. Anticipatory and anticipated emotions were shown to independently motivate goal-directed behavior, and these effects emerged even while controlling for the likelihood of negative outcomes, an important cognitive factor, and future anxiety, a relevant emotional disposition. These findings are new and support the proposed framework of future-oriented emotions.

The analyses also indicated, first, that the motivational effects of anticipated emotions are stronger than those of anticipatory emotions and, second, that negative emotions are more powerful determinants of behavioral intentions than positive emotions. With regard to the first point, the combined (absolute) standardized effects of positive and negative anticipatory emotions on behavioral intentions was .16 ( -.01 and .15 , respectively), whereas the combined effect of positive and negative anticipated emotions was .39 (.12 and .27 , respectively), which is more than twice as large. Future research will have to explore whether this is a general result or whether there are circumstances in which anticipatory emotions are a stronger motivator of behavior. Concerning the second point, for both anticipatory and anticipated emotions, negative affect led to stronger behavioral intentions than positive affect. On the one hand, this result is consistent with the finding that negative information often has more powerful effects on information processing, persuasion, and behavior than positive information (negativity effect; see Peeters \& Czapinski, 1990; Tversky \& Kahneman, 1981). On the other hand, the future event studied in this research was a threat that people tried to avoid or limit by engaging in anticipatory coping behavior. Perhaps negative emotions are more important motivators of behavior when the future event is associated with undesired outcomes, whereas positive emotions might have more potent effects when the future outcomes are desired, a speculation which follow-up research may test.

In the case of anticipated emotions, the behavioral effects of both positive and negative affect were significant. In contrast, and different from our predictions, positive anticipatory emotions did not significantly influence behavioral intentions. We speculate that this is due to the target of the positive anticipatory emotions. Specifically, a person may hope that the future state of the world will be desirable, or that the outcomes of behavior to cope with the event are desirable (coping potential or agency thoughts) (Snyder, Rand, \& Sigmon, 2000). Hope is expected to have motivational effects if a person is confident and optimistic that he or she can do something to achieve positive outcomes. In contrast, if a person hopes that the desired outcomes will occur automatically, there is little incentive to take action (see Oettingen, Pak, \& Schnetter, 2001). To clarify this, consider a person who is ill and hopes that a cure will be found for the illness. This person is unlikely to do much. On the other hand, a person who hopes that eating healthy food will cure the illness is likely to be motivated to perform this instrumental behavior. Our present research could not distinguish between potentially different targets of hope and their behavioral effects, since the emotion was linked to the final outcomes for the person, which might result directly from the event not producing undesired outcomes or from the positive effects of the coping behavior.

Anticipated emotions, and the underlying process of mental simulation, are in some ways similar to subjective expected utility models, such as expectancy-value models (Fishbein \& Ajzen, 1975). Thus, one may argue that the utility or value component in these models is analogous to anticipated emotions. However, while subjective expected utility models are based on a rational calculus that combines estimates of the likelihood of certain outcomes with an assessment of the utility of these outcomes, anticipated emotions are not focused on the likelihood that certain outcomes will occur and they are potentially much more 'hot' than the 'cold' deliberations about value implicit in subjective expected utility models. In support of this reasoning, research has shown that anticipated emotions, in particular anticipated regret, has incremental effects on goal-directed behavior over and above the effects of attitudes and subjective norms, which should mediate the subjective expected utility effects (Abraham \& Sheeran, 2004; Richard et al., 1995, 1996; Zeelenberg \& Pieters, 2004).

Our conceptualization of anticipatory and anticipated emotions assumes that the two types of future-oriented emotions are fuzzy sets characterized by graded membership structure. ${ }^{4}$ This implies that there are certain emotions that do not fall

${ }^{4}$ We thank the editor and reviewers for stimulating this discussion. 
neatly into one of the two categories. Following Frijda (2004), we have argued that anticipated emotions are often virtual in the sense that they capture forecasts of one's future emotions. However, such mental simulations about future states may lead to actually experiencing the future emotion at present, when the affective forecast leads to the feelings, thoughts, emotivational goals, and action tendencies that accompany actual emotions. Consider the situation of contemplating the joy that one will experience during one's birthday party, before the first guests arrive. Such a mental simulation might gladden us, and anticipated joy may lead to experienced joy. This joy about a future event is called 'Vorfreude' in German and 'voorpret' in Dutch (literally pre-joy), and it may be translated as pleasant anticipation. Although this emotion shares some similarities with anticipatory emotions because it is a phenomenologically 'real' affective reaction that is experienced in the present, not an affective forecast of some hypothetical future scenario, we would not classify it as an anticipatory emotion in our terminology (at least not as an unambiguous example of anticipatory emotions) because uncertainty is not a defining characteristic of this emotional experience. As another example, consider the emotion of fear or anxiety. In our conceptualization, fear is the prototype of negative anticipatory emotions. However, fear could also be experienced as an anticipated emotion. For example, somebody could visualize that a dreaded event has actually occurred and experience fear as a consequence ('suppose that the doctor tells me in a week from now that I have a terminal form of cancer, how much would I fear death?'). Ortony et al. (1988) use the terms fears-confirmed or worst fears realized to refer to such situations. In cases where these affective reactions are forecast pre-factually, we would classify them as anticipated emotions. Future research should investigate the conditions that turn affective forecasts into actual emotional experiences, and whether some individuals are more prone to such transitions than others.

To return to our original inspiration, this research found that positive and negative anticipatory and anticipated emotions are conceptually and empirically distinct, are driven by different mechanisms, and can independently motivate goal-directed behavior, even while controlling for important cognitive and emotional trait factors. This reveals the implications of the experienced and imagined affect about what the future holds in stock for us, and supports the construct and predictive validity of these distinct types of future-oriented emotions.

\section{REFERENCES}

Ajzen, I. (1991). The theory of planned behavior. Organizational Behavior and Human Decision Processes, 50, 179-210.

Abraham, C., \& Sheeran, P. (2004). Deciding to exercise: The role of anticipated regret. British Journal of Health Psychology, 9, 269-278.

Atkinson, J. W. (1964). An introduction to motivation. Princeton, NJ: Van Nostrand.

Averill, J. R., Catlin, G., \& Chon, K. K. (1990). Rules of hope. New York: Springer.

Bagozzi, R. P., Baumgartner, H., \& Pieters, R. (1998). Goal-directed emotions. Cognition and Emotion, 12, 1-26.

Bagozzi, R. P., \& Heatherton, T. F. (1994). A general approach to representing multifaceted personality constructs: Application to state self-esteem. Structural Equation Modeling, 1, 35-67.

Boster, F. J., \& Mongeau, P. (1984). Fear-arousing persuasive messages. In R. N. Bastrow, \& B. H. Westley (Eds.), Communication yearbook (Vol. 8, pp. 330-375). Beverly Hills, CA: Sage.

Carver, C. S., \& Scheier, M. F. (2002). Optimism. In C. R. Snyder, \& S. Lopez (Eds.), Handbook of positive psychology (pp. 231-243). Oxford, England: Oxford University Press.

Fehr, B., \& Russell, J. A. (1984). Concept of emotion viewed from a prototype perspective. Journal of Experimental Psychology: General, 113, 464-486.

Fishbein, M., \& Ajzen, I. (1975). Belief, attitude, intention, and behavior: An introduction to theory and research. Reading, MA: Addison-Wesley.

Frijda, N. H., Kuipers, P., \& ter Schure, E. (1989). Relations among emotion, appraisal, and emotional action readiness. Journal of Personality and Social Psychology, 57, 212-228.

Frijda, N. H. (2004). Emotion and action. In A. S. R. Manstead, N. Frijda, \& A. Fischer (Eds.), Feelings and emotions: The Amsterdam symposium (pp. 158-173). Cambridge, England: Cambridge University Press.

Gilbert, D. T., Pinel, E. C., Wilson, T. D., Blumberg, S. J., \& Wheatley, T. P. (1998). Immune neglect: A source of durability bias in affective forecasting. Journal of Personality and Social Psychology, 75, 617-638.

Gleicher, F., Boninger, D. S., Strathman, A., Armor, D., \& Ahn, M. (1995). With an eye toward the future: The impact of counterfactual thinking on affect, attitudes, and behavior. In N. J. Roese, \& J. M. Olson (Eds.), What might have been: The social psychology of counterfactual thinking (pp. 283-304). Mahwah, New Jersey: Erlbaum.

Hu, L., \& Bentler, P. M. (1999). Cutoff criteria for fit indexes in covariance structure analysis: Conventional criteria versus new alternatives. Structural Equation Modeling, 6, 1-55.

Hyatt, M. S. (1998). The millennium bug: How to survive the coming chaos. New York: Broadway Books. 
Lazarus, R. S. (1991). Emotion and adaptation. New York: Oxford University Press.

Loewenstein, G., \& Lerner, J. S. (2003). The role of affect in decision making. In R. J. Davidson, K. R. Scherer, \& H. H. Goldsmith (Eds.), Handbook of affective sciences (pp. 619-642). Oxford: Oxford University Press.

Milne, S., Sheeran, P., \& Orbell, S. (2000). Prediction and intervention in health-related behavior: A meta-analytic review of protection motivation theory. Journal of Applied Social Psychology, 30, 106-143.

Öhman, A. (2000). Fear and anxiety: Evolutionary, cognitive, and clinical perspectives. In M. Lewis, \& J. M. Haviland-Jones (Eds.), Handbook of emotions (2nd ed., pp. 573-593). New York: The Guilford Press.

Oettingen, G., Pak, H., \& Schnetter, K. (2001). Self-regulation of goal setting: Turning free fantasies about the future into binding goals. Journal of Personality and Social Psychology, 80, 736-753.

Ortony, A., Clore, G. L., \& Collins, A. (1988). The cognitive structure of emotions. Cambridge, England: Cambridge University Press.

Parker, D., Manstead, A. S. R., \& Stradling, S. G. (1995). Extending the theory of planned behaviour: The role of personal norm. British Journal of Social Psychology, 34, 127-137.

Peeters, G., \& Czapinski, J. (1990). Positive-negative asymmetry in evaluations: The distinction between affective and informational negativity effects. European Review of Social Psychology, 1, 33-60.

Perugini, M., \& Bagozzi, R. P. (2001). The role of desires and anticipated emotions in goal-directed behaviors: Broadening and deepening the theory of planned behavior. British Journal of Social Psychology, 40, 79-98.

Plutchik, R. (1980). Emotions: A psychoevolutionary synthesis. New York: Harper \& Row.

Richard, R., van der Pligt, J., \& de Vries, N. (1995). Anticipated affective reactions and prevention of AIDS. British Journal of Social Psychology, 34, 9-21.

Richard, R., van der Pligt, J., \& de Vries, N. (1996). Anticipated affect and behavioral choice. Basic and Applied Social Psychology, 18, $111-129$.

Roseman, I. J., Antoniou, A. A., \& Jose, P. E. (1996). Appraisal determinants of emotions: Constructing a more accurate and comprehensive theory. Cognition and Emotion, 10, 241-277.

Shaver, P., Schwartz, J., Kirston, D., \& O’Connor, C. (1987). Emotion knowledge: Further exploration of a prototype approach. Journal of Personality and Social Psychology, 52, 1061-1086.

Smith, C. A., \& Ellsworth, P. C. (1985). Patterns of cognitive appraisal in emotion. Journal of Personality and Social Psychology, 48, 813-838.

Snyder, C. R., \& Lopez, S. (2002). Handbook of positive psychology. Oxford, England: Oxford University Press.

Snyder, C. R., Rand, K. L., \& Sigmon, D. R. (2000). Hope theory: A member of the positive psychology theory. In C. R. Snyder, \& S. Lopez (Eds.), Handbook of positive psychology (pp. 257-276). Oxford, England: Oxford University Press.

Sutton, S. R. (1982). Fear-arousing communications: A critical examination of theory and research. In J. R. Eiser (Ed.), Social psychology and behavioral medicine (pp. 303-337). New York: John Wiley.

Taylor, S. E., \& Pham, L. B. (1996). Mental simulation, motivation, and action. In P. M. Gollwitzer, \& J. A. Bargh (Eds.), The psychology of action: Linking cognition and motivation to behavior (pp. 219-235). New York: Guilford.

Tversky, A., \& Kahneman, D. (1981). The framing of decisions and the psychology of choice. Science, 211, $453-458$.

van der Pligt, J., Zeelenberg, M., van Dijk, W. W., de Vries, N. K., \& Richard, R. (1998). Affect, attitudes and decisions: Let's be more specific. In W. Stroebe, \& M. Hewstone (Eds.), European review of social psychology 8, 34-66.

Wilson, T. D., \& Gilbert, D. T. (2003). Affective forecasting. Advances in Experimental Social Psychology, 35, $346-412$.

Zeelenberg, M. (1999). Anticipated regret, expected feedback and behavioral decision-making. Journal of Behavioral Decision Making, $12,93-106$.

Zeelenberg, M., \& Pieters, R. (2004). Consequences of regret aversion in real life: The case of the Dutch postcode lottery. Organizational Behavior and Human Decision Processes, 93, 155-168.

Zaleski, Z. (1996). Future anxiety: Concept, measurement, and preliminary research. Personality and Individual Differences, 21, 165-174. 